\title{
Bonding stability of adhesive systems to eroded dentin
}

\section{Janaina Barros CRUZ(a) Gabriela BONINI(a) \\ Tathiane Larissa LENZI (b) José Carlos Pettorossi IMPARATO(c) Daniela Prócida RAGGIO(c)}

(a)Faculdade São Leopoldo Mandic - SLMandic, School of Dentistry, Centro de Pesquisas Odontológicas - CPO, Campinas, SP, Brazil.

(b) Universidade Federal de Santa Maria UFSM, School of Dentistry, Post Graduate Program in Dental Science, Santa Maria, RS, Brazil.

(c) Universidade de São Paulo - USP, School of Dentistry, Department of Orthodontics and Pediatric Dentistry, São Paulo, SP, Brazil.

Declaration of Interests: The authors certify that they have no commercial or associative interest that represents a conflict of interest in connection with the manuscript.

Corresponding Author:

Tathiane Larissa Lenzi

E-mail: tathilenzi@usp.br

DOI: 10.1590/1807-3107BOR-2015.vol29.0088

Submitted: Sep 09, 2014

Accepted for publication: Mar 14, 2015

Last revision: Jun 09, 2015
Abstract: This in vitro study evaluated the immediate and 6 months microshear bond strength ( $\mu \mathrm{SBS}$ ) of different adhesive systems to sound and eroded dentin. Sixty bovine incisors were embedded in acrylic resin and ground to obtain flat buccal dentin surfaces. Specimens were randomly allocated into two groups: sound dentin (immersion in artificial saliva) and eroded dentin (erosive challenge following a $\mathrm{pH}$ cycling model comprising $4 \times$ /day Sprite Light ${ }^{\circledR}$ drink for 10 days). Then, specimens were reassigned according to the adhesive system: etch-and-rinse adhesive (Adper Single Bond), two-step self-etch system (Clearfil SE Bond), or one-step self-etch adhesive (Adper Easy One). Polyethylene tubes with an internal diameter of $0.76 \mathrm{~mm}$ were placed over pre-treated dentin and filled with resin composite (Z250). Half of the specimens were evaluated by the $\mu$ SBS test after $24 \mathrm{~h}$, and the other half 6 months later, after water storage at $37^{\circ} \mathrm{C}$. Failure mode was evaluated using a stereomicroscope (400×). Data were analyzed by three-way repeated measures analysis of variance and Tukey's post hoc tests $(\alpha=0.05)$. After 6 months of water aging, marked reductions in $\mu$ SBS values were observed, irrespective of the substrate. The $\mu$ SBS values for eroded dentin were lower than those obtained for sound dentin. No difference in bonding effectiveness was observed among adhesive systems. For all groups, adhesive/mixed failure was observed. In conclusion, eroded dentin compromises the bonding quality of adhesive systems over time.

Keywords: Tooth Erosion; Dentin-Bonding Agents; Shear Strength.

\section{Introduction}

An increase in the prevalence of tooth wear in all ages and different populations $s^{1,2}$ relates to several factors such as higher consumption of acidic foods and gastro esophageal disorders. ${ }^{3,4}$

This has attracted worldwide research interest and studies have shown that the severity of dental erosion is majorly restricted to the enamel. ${ }^{2,5}$ However, without controlling etiological factors, the erosive wear can result in dentin exposure over time. ${ }^{6}$

In such cases, restorative treatment is necessary to reduce thermal sensitivity; prevent pulpal involvement; re-establish tooth contour, function, and esthetics; and increase tooth resistance. ${ }^{7}$ Currently, adhesive systems associated with resin composite are considered as the most appropriate restorative option because these are more resistant to acidic 
conditions than resin-modified and conventional glass ionomer cements. ${ }^{8}$

De and remineralization erosive processes lead to greater wear ${ }^{9}$ and softening of the outermost dentin layer ${ }^{10}$ compared with sound dentin. In addition, erosion can remove dentinal plugs and organic intertubular dentin, in turn increasing tubule diameter and collagen exposure. ${ }^{11}$ Therefore, adhesive materials must adhere to different surfaces than those for which they were originally created and tested, which generates uncertainty regarding their longevity in this structurally altered substrate. Thus, studies on adhesion to eroded dentin are imperative.

The bonding of adhesive systems to eroded dentin has been poorly investigated, ${ }^{12,13}$ particularly regarding its long-term effectiveness..$^{14}$ Moreover, majority of the results vary. Whereas the bond strength of adhesive systems to eroded dentin has been shown to be lower compared with that of sound dentin, ${ }^{14}$ it has been also demonstrated that eroded dentin does not jeopardize the immediate bond strength of the adhesive restorative materials. ${ }^{13}$

Thus, the aim of this in vitro study was to evaluate the bond strength stability of adhesive systems to sound and eroded dentin.

\section{Methodology}

\section{Tooth Selection and Preparation}

Sixty bovine incisors stored at $4^{\circ} \mathrm{C}$ were used in this study. The roots were removed using a low-speed diamond disc in a cutting machine (Labcut 1010, Extec Co., Enfield, USA) and crowns were embedded in self-curing acrylic resin inside polyvinyl chloride rings (JET Clássico ${ }^{\circledR}$, São Paulo, Brazil). The exposed buccal surfaces were ground under water using a 320-grit $\mathrm{SiC}$ paper to obtain flat dentin surfaces and further polished using 600-grit $\mathrm{SiC}$ paper for $60 \mathrm{~s}$ to create a standardized smear layer.

\section{Erosive Challenge}

Specimens were randomly allocated into two groups: (1) immersion in artificial saliva during the experimental period (control group/sound dentin, $n=30$ ) and (2) exposure to erosion challenge according to a $\mathrm{pH}$-cycling mode $\mathrm{l}^{15}$ (eroded dentin, $\mathrm{n}=30$ ).
For 10 days, the erosive cycles were conducted by immersing teeth in Sprite Light ${ }^{\circledast}(30 \mathrm{~mL} /$ sample; Coca-Cola Co., Spal, Porto Real, Brazil) for 1 min, followed by immersion in artificial saliva (30 mL/sample) for 59 minutes. This procedure was consecutively repeated four times per day at room temperature ${ }^{15}$ Each day, during the remaining $20 \mathrm{~h}$, the teeth were maintained in artificial saliva. The Sprite Light ${ }^{\circledR}(\mathrm{pH} 2.87)$ had a buffering capacity of $0.375 \pm 0.01$, which was equivalent to $0.375 \mathrm{~mL}$ of $0.2 \mathrm{MNaOH} / 3 \mathrm{~mL}$ of the beverage, for an increase of $1 \mathrm{pH}$ unit. The composition of the artificial saliva was $1.5 \mathrm{mM} \mathrm{Ca}\left(\mathrm{NO}_{3}\right)_{2} \cdot 4 \mathrm{H}_{2} \mathrm{O}, 0.9 \mathrm{mM} \mathrm{NaH} \mathrm{PO}_{4} \cdot 2 \mathrm{H}_{2} \mathrm{O}$, $150 \mathrm{mM} \mathrm{KCl}, 0.1 \mathrm{M}$ Tris buffer, 0.03 ppm fluoride, and $\mathrm{pH} 7.0 .^{16}$

\section{Restorative Procedures}

Teeth from each dentin substrate (sound or eroded) were randomly reassigned into three subgroups $(\mathrm{n}=10)$, according to the adhesive system used: Adper Single Bond 2 (SB; 3M ESPE, Saint Paul, USA), Clearfil SE Bond (CSEB; Kuraray Medical Inc., Tokyo, Japan), and Adper Easy One (EASY; 3M ESPE, Saint Paul, USA). Table 1 displays the main components and application mode of these adhesive systems.

After adhesive systems' application, according to manufacturers' instructions, polyethylene tubes (Micro-bore $^{\circledR}$ Tygon S-54-HL Medical Tubing, Saint-Gobain Performance Plastics, Akron, USA) with an internal diameter of $0.76 \mathrm{~mm}$ and height of $1.0 \mathrm{~mm}$ were positioned over the dentin surfaces. Then, the adhesives were light cured using a halogen light-curing unit (Jetlite 4000 Plus, J. Morita USA; Irvine, USA) with $600 \mathrm{~mW} / \mathrm{cm}^{2}$ power density. The device's own radiometer quantified the output power. The tubes were filled with resin composite (Filtek Z250, 3M ESPE, Saint Paul, USA) and light cured. For each tooth, four specimens were built up. A trained operator conducted all bonding and restorative procedures at room temperature.

\section{Microshear Bond Strength ( $\mu$ SBS) Test}

After storage in distilled water at $37^{\circ} \mathrm{C}$ for $24 \mathrm{~h}$, the polyethylene tubes were removed using a surgical blade, which resulted in cylindrical specimens with a cross-sectional area of approximately $0.45 \mathrm{~mm}^{2}$. 
Table 1. Materials, manufacturers, main components, $\mathrm{pH}$, and application mode.

\begin{tabular}{|c|c|c|c|}
\hline Adhesive system (Manufacturer) & Main components & $\mathrm{pH}^{*}$ & Application mode \\
\hline $\begin{array}{l}\text { SB } \\
\text { Adper Single Bond } 2 \\
\text { (3M ESPE, St. Paul, USA) }\end{array}$ & $\begin{array}{l}\text { Etchant: } 35 \% \text { phosphoric acid } \\
\text { HEMA, water, ethanol, bis-GMA, dimethacrylates, } \\
\text { amines, metacrylate functional copolymer of } \\
\text { polyacrylic and polyitaconic acids, } 10 \% \text { by weight of } \\
5 \mathrm{~nm} \text {-diameter spherical silica particles. }\end{array}$ & $\begin{array}{l}0.6 \\
4.7\end{array}$ & $\begin{array}{l}\text { Etch for } 15 \mathrm{~s} \text {. } \\
\text { Rinse with water spray for } 15 \mathrm{~s} \text {, leaving tooth moist. } \\
\text { Active application of two consecutive coats of the } \\
\text { adhesive with a fully saturated brush tip. Dry gently } \\
\text { for } 2-5 \mathrm{~s} \text {. } \\
\text { Light cure for } 10 \mathrm{~s} \text {. }\end{array}$ \\
\hline $\begin{array}{l}\text { CSEB } \\
\text { Clearfil SE Bond } \\
\text { (Kuraray Medical Inc., Tokyo, } \\
\text { Japan) }\end{array}$ & $\begin{array}{l}\text { Primer: MDP, HEMA, hydrophilic dimethacrylate, } \\
\text { dl-campherquinone, N,N-diethanol-p-toluidine, water } \\
\text { Bonding: MDP, Bis-GMA, HEMA, hydrophobic } \\
\text { dimethacrylate, dl-campherquinone, } \\
\text { N,N-diethanol-p-toluidine, silanated colloidal silica }\end{array}$ & 2.0 & $\begin{array}{l}\text { Apply primer on dry surface for } 20 \mathrm{~s} . \\
\text { Slight air drying. } \\
\text { Apply bonding. } \\
\text { Light cure for } 10 \mathrm{~s} .\end{array}$ \\
\hline $\begin{array}{l}\text { EASY } \\
\text { Adper Easy One } \\
\text { (3M ESPE, St. Paul, USA) }\end{array}$ & $\begin{array}{l}\text { HEMA, water, ethanol, Bis-GMA, dimethacrylates, } \\
\text { amines, metacrylate functional copolymer of } \\
\text { polyacrylic and polyitaconic acids, } 10 \% \text { by weight of } \\
5 \mathrm{~nm} \text {-diameter spherical silica particles, phosphate } \\
\text { ester of methacrylate. }\end{array}$ & 2.7 & $\begin{array}{l}\text { Apply one coat of adhesive with a fully saturated } \\
\text { brush tip for } 20 \mathrm{~s} . \\
\text { Dry gently for } 5 \mathrm{~s} \text {. } \\
\text { Light cure for } 10 \mathrm{~s} \text {. }\end{array}$ \\
\hline
\end{tabular}

Abbreviations: MDP: 10-methacryloyloxydecyl-dihydrogen-phosphate; Bis-GMA: bisphenyl-glycidyl methacrylate; HEMA: 2-hydroxyethyl methacrylate). ${ }^{*} \mathrm{pH}$ values were provided by the manufacturers.

Specimens were examined under a stereomicroscope at 20× magnification (Discovery V20, Zeiss, Berlin, Germany), and those with interfacial gaps, bubble inclusion, or other defects were excluded and replaced. Only two specimens were substituted.

Half of the specimens from of each tooth were immediately evaluated by $\mu$ SBS. The specimens were individually attached to a universal testing machine (Kratos Industrial Equipment, Cotia, Brazil). A thin steel wire $(0.20 \mathrm{~mm}$ diameter $)$ was looped flush between the load cell projection and resin composite cylinder making contact with the lower half-circumference of the cylinder and touching the dentin surface. A shear load was applied at a crosshead speed of $1.0 \mathrm{~mm} / \mathrm{min}$, until failure occurred. The cylinder was maintained in line with the center of the load cell, and the wire loop was parallel to the load cell movement direction and to the bonding interface. The fracture load was recorded and the bond strength was expressed in MPa.

The other half underwent $\mu$ SBS only after 6 months of storage in distilled water containing $0.4 \%$ sodium azide at $37^{\circ} \mathrm{C}$. The storage solution was not changed and its $\mathrm{pH}$ was monitored each month.

\section{Failure mode}

All debonded specimens were observed in a stereomicroscope (HMV II, Shimadzu, Kyoto, Japan) at $400 \times$ magnification to determine failure mode: adhesive/mixed (failure at the resin-dentin interface or mixed with cohesive failure of the neighboring substrate) or cohesive (failure exclusively within the dentin or resin composite). The specimens that debonded during preparation or water storage period (pretesting or premature failures) were also recorded.

\section{Statistical analysis}

The experimental unit in this study was the hemi-tooth because half of the sample was tested immediately, and the other half after, 6 months. Thus, the mean of $\mu$ SBS (MPa) values of two specimens of a hemi-tooth was averaged for statistical purposes. The $\mu$ SBS mean for every testing group was expressed as the average of the 10 hemi-teeth used per group.

Normal distribution of bond strength data and equality of variances were assumed after Kolmogorov-Smirnov and Cochran tests, respectively. The $\mu$ SBS means were analyzed using three-way repeated measures analysis of variance (substrate vs. adhesive system vs. storage period) and Tukey's post hoc test $(\alpha=0.05)$. The repeated measure was the storage period. Statistical analysis was performed using the GMC software, version 7.7 (FORP USP, Ribeirão Preto, Brazil). Failure mode was only evaluated descriptively.

\section{Results}

$\mu S B S$ (MPa) and standard deviations for all experimental groups are summarized in Table 2. 
The factors substrate $(\mathrm{p}=0.01)$ and storage period $(p<0.01)$ were statistically significant.

The $\mu$ SBS values of eroded dentin were lower than those obtained for sound dentin. The bond strength decreased after 6 months of water storage, independent of the substrate. No difference in bonding effectiveness was observed among the adhesive systems.

Figure summarizes the distribution of failure. A predominance of adhesive/mixed failures was observed, whereas no cohesive failures in dentin were verified. Pretesting failures were only observed after 6 months of water aging.

\section{Discussion}

Because of limited scientific evidence on bonding to eroded dentin and of the chemical and microstructural changes in dental substrates arising of erosive challenge, the long-term performance of restorative materials in this type of substrate remains uncertain. Therefore, this investigation evaluated the immediate and 6 months bond strength of different adhesive systems to sound and eroded dentin.

In this study, bovine teeth were used as an appropriate substitute for human dentin because of their relatively close resemblance to their human counterparts. ${ }^{17}$ In addition, bovine dentin offers acid resistance similar to that of human dentin. ${ }^{18}$

To simulate dental erosion, the $\mathrm{pH}$-cycling model using a citric acid drink was employed. This beverage has a high erosive potential due to its low $\mathrm{pH}$ and low fluoride/calcium concentrations. ${ }^{15}$ Although in vitro protocols are fail to reproduce the exact in vivo conditions in clinical settings, the model using cyclic conditions with very short exposure to acids and their removal by saliva appropriately reflects the erosive challenge observed in the oral cavity. ${ }^{19}$ Moreover, this model simulates regular intake of acidic drinks that are considered as risks for dental erosion. ${ }^{19}$

The $\mu$ SBS values obtained with eroded dentin were lower than those obtained for sound dentin, as also previously reported. ${ }^{12,14}$ The erosion process can result in mineral loss, fibril collagen exposure, and opening of dentinal tubules. ${ }^{14}$ The higher degree of demineralization in eroded dentin results in deeper demineralized layer, which after adhesive penetration, allows formation of hybrid layers thicker than those in sound dentin. These layers are structurally imperfect and contain porosities, ${ }^{20}$ which in turn cause areas of hydrophilic predominance and demineralized zones devoid of resin reinforcement; this may contribute to lower $\mu$ SBS values for eroded dentin because resin monomers may not penetrate as deeply as acid. ${ }^{21}$ Furthermore, the greater collagen exposure creates sites that are more prone to undergo degradation over time. ${ }^{22}$ In severe erosive cases, dentin exposure may lead to a sclerotic dentin substrate with a hypermineralized shiny surface layer accomplished by tubular occlusion. ${ }^{23}$

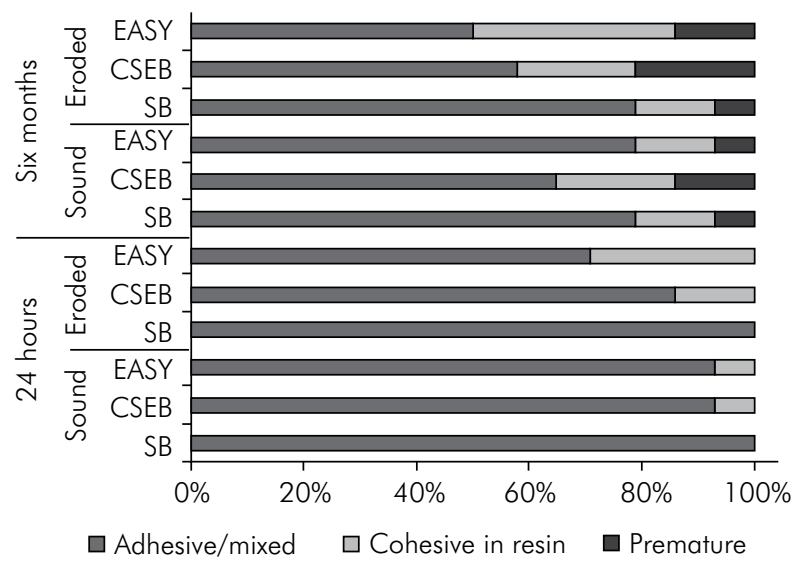

Figure. Failure mode distribution (\%).

Table 2. $\mu \mathrm{SBS}(\mathrm{MPa})$ means and standard deviations for all experimental groups $\left({ }^{*}\right)$.

\begin{tabular}{|c|c|c|c|c|}
\hline \multirow{2}{*}{$\begin{array}{l}\text { Storage period } \\
\text { Adhesive/Substrate }\end{array}$} & \multicolumn{2}{|c|}{$24 \mathrm{~h}$} & \multicolumn{2}{|c|}{6 months } \\
\hline & Sound dentin & Eroded dentin & Sound dentin & Eroded dentin \\
\hline Adper Single Bond 2 & $14.11 \pm 2.73^{\mathrm{A}, \mathrm{a}}$ & $11.80 \pm 3.55^{\mathrm{A}, \mathrm{b}}$ & $8.05 \pm 1.84^{\mathrm{B}, \mathrm{a}}$ & $6.49 \pm 1.77^{\mathrm{B}, \mathrm{b}}$ \\
\hline Clearfil SE Bond & $12.23 \pm 4.81^{A, a}$ & $10.89 \pm 4.03^{\mathrm{A}, \mathrm{b}}$ & $9.83 \pm 2.94^{\mathrm{B}, \mathrm{a}}$ & $6.45 \pm 2.57^{B, b}$ \\
\hline Adper Easy One & $11.75 \pm 4.23^{\mathrm{A}, \mathrm{a}}$ & $9.17 \pm 2.59^{A, b}$ & $7.79 \pm 3.45^{\mathrm{B}, \mathrm{a}}$ & $4.83 \pm 1.85^{\mathrm{B}, \mathrm{b}}$ \\
\hline
\end{tabular}

$\left(^{*}\right)$ Different superscript lower letters indicate a statistically significant difference between substrates.

$(p<0.05)$. Different superscript capital letters indicate a statistically significant difference between storage periods $(p<0.05)$. 
The in vitro model used in this study promotes a substrate with a superficial demineralized layer, simulating initial erosion. The worse performance of adhesive systems in artificially-created eroded dentin compared with sound dentin supports the fact that the protocol is suitable for testing bond strength of eroded dentin. However, it should not replace natural eroded dentin when the use of this substrate is possible. The limitation of this type of simulation in extracted teeth is that the reaction of the dentin-pulp complex to the demineralization process, which is represented by sclerotic dentin, is not present, thus differing from the clinical situation.

Degradation of resin-dentin bonds was observed in this study, represented by a decrease in $\mu$ SBS values after 6 months of water storage, irrespective of the substrate. A previous study ${ }^{14}$ demonstrated that 1 year of storage lowered the bond strength values, although this aging effect was more pronounced for eroded surfaces compared with that for sound dentin. Methodological differences in the storage time and bond strength test (microshear vs. microtensile) may explain these controversial findings.

Metalloproteinases (MMPs) represent a family of zinc- and calcium-dependent endopeptidases present in dentin and saliva and are capable of degrading extracellular matrix components, including collagen, in native and denatured forms. ${ }^{24}$ These enzymes are exposed and activated when dentin is solubilized. Dentin erosion is a complex process characterized by mineral dissolution, which exposes the organic matrix to breakdown by bacteria and host-derived enzymes, such as MMPs. ${ }^{25}$ Enzymatic removal of the organic matrix by MMPs increases demineralization because the demineralized organic matrix hampers ionic diffusion after an acidic challenge, ${ }^{25}$ and subsequently, accelerates the bond degradation to eroded dentin.

The bonding effectiveness to both substrates did not depend on the adhesives tested. Zimmerli et al. ${ }^{14}$ demonstrated that etch-and-rinse adhesive system showed a superior bonding performance in sound dentin, whereas the self-etch adhesive system (CSEB) showed better results in eroded dentin. CSEB has an acid primer, which promotes simultaneous demineralization and monomer infiltration, preventing denuding of collagen layer, as verified using phosphoric acid. ${ }^{26}$ Moreover, the protective effect of both resin-coated collagen and calcium salts of 10-methacryloxydecyl dihydrogen phosphate ${ }^{27}$ may explain the superior bonding produced by CSEB in eroded dentin. Nevertheless, this study did not verify this difference.

The SB and EASY adhesives have similar compositions, except the presence acidic monomer in the one-step self-etching system. We speculated that due to the mild-aggressiveness of the self-etching primer $(\mathrm{pH}=2.7)$, EASY could show better performance in eroded dentin, because of a decrease in the depth of the demineralized layer, which reduces the difference between the depth to which the substrate is demineralized to which monomer can infiltrate. However, this was not observed in this study and further studies are required to test this hypothesis. In another study, a similar performance of self-etch adhesive systems in sound dentin was observed. ${ }^{28}$

We did not perform adhesive area delimitation, although this could have resulted in less questionable outcomes. ${ }^{29}$ Shimaoka et al..$^{29}$ reported significantly higher bond strength values when the bonding area was not confined with perforated tape. ${ }^{29}$ Because the adhesive was applied on the dental substrate, it was highly difficult to guarantee that the area being tested was restricted to the circumference of the composite cylinder. However, our immediate results were similar to those of a previous study ${ }^{29}$ with delimitation of adhesive area. Moreover, Andrade et $a l .{ }^{30}$ showed that different bonded surface areas did not apparently affect $\mu$ SBS when the adhesive area was not delimitated. Further studies are needed to test this methodological aspect.

It has recently been show $\mathrm{n}^{13}$ that adhesive systems are preferable to glass ionomer cements for restoring eroded tooth dentin. However, because bond deterioration occurred for all adhesive systems after 6 months of water aging, further studies evaluating factors that increase the longevity of resin-dentin bonds created on eroded substrate such as the use of MMPs' inhibitors, should be conducted.

\section{Conclusion}

Eroded dentin compromises the quality of bonding over time, irrespective of adhesive type. 


\section{References}

1. Kazoullis S, Seow WK, Holcombe T, Newman B, Ford D. Common dental conditions associated with dental erosion in schoolchildren in Australia. Pediatr Dent. 2007 Jan-Feb;29(1):33-9.

2. Murakami C, Oliveira LB, Sheiham A, Correa MSNP, Haddad $\mathrm{AE}$, Bonecker M. Risk indicators for erosive tooth wear in Brazilian preschool children. Caries Res. 2011;45(2):121-9.

3. Lussi A, Jaeggi T, Zero D. The role of diet in the aetiology of dental erosion. Caries Res. 2004;38 Suppl 1:34-44.

4. Imfeld T. Dental erosion. Definition, classification and links. Eur J Oral Sci. 1996 Apr;104(2):151-5.

5. Dugmore CR, Rock WP. The prevalence of tooth erosion in 12-year-old children. Br Dent J. 2004 Mar;196(5):279-82.

6. Jaeggi T, Gruninger A, Lussi A. Restorative therapy of erosion. Monogr Oral Sci. 2006;20:200-14.

7. Wang X, Lussi A. Assessment and management of dental erosion. Dent Clin North Am. 2010 Jul;54(3):565-78.

8. Honorio HM, Rios D, Francisconi LF, Magalhaes AC, Machado MA, Buzalaf MA. Effect of prolonged erosive $\mathrm{pH}$ cycling on different restorative materials. J Oral Rehabil. 2008 Dec;35(12):947-53.

9. Turssi CP, Hara AT, Domiciano SJ, Serra MC. Study on the potential inhibition of root dentine wear adjacent to fluoride-containing restorations. J Mater Sci Mater Med. 2008 Jan;19(1):47-51.

10. Wongkhantee S, Patanapiradej V, Maneenut C, Tantbirojn D. Effect of acidic food and drinks on surface hardness of enamel, dentine, and tooth-coloured filling materials. J Dent. 2006 Mar;34(3):214-20.

11. Prati C, Montebugnoli L, Suppa P, Valdre G, Mongiorgi R. Permeability and morphology of dentin after erosion induced by acidic drinks. J Periodontol. 2003 Apr;74(4):428-36.

12. Ramos TM, Ramos-Oliveira TM, Freitas PM, Azambuja Jr N, Esteves-Oliveira M, Gutknecht N, et al. Effects of Er:YAG and Er,Cr:YSGG laser irradiation on the adhesion to eroded dentin. Lasers Med Sci. 2015 Jan;30(1):17-26. Epub 2013 May 7.

13. Cruz JB, Lenzi TL, Tedesco TK, Guglielmi CA, Raggio DP. Eroded dentin does not jeopardize the bond strength of adhesive restorative materials. Braz Oral Res. 2012 Jul-Aug;26(4):306-12.

14. Zimmerli B, De Munck J, Lussi A, Lambrechts P, Van Meerbeek B. Long-term bonding to eroded dentin requires superficial bur preparation. Clin Oral Investig. 2012 Oct;16(5):1451-61.

15. Magalhaes AC, Rios D, Machado MA, Silva SM, Lizarelli RF, Bagnato VS, et al. Effect of Nd:YAG irradiation and fluoride application on dentine resistance to erosion in vitro. Photomed Laser Surg. 2008 Dec;26(6):559-63.

16. Vieira AE, Delbem AC, Sassaki KT, Rodrigues E, Cury JA, Cunha RF. Fluoride dose response in $\mathrm{pH}$-cycling models using bovine enamel. Caries Res. 2005 Nov-Dec;39(6):514-20.
17. Schilke R, Lisson JA, Bauss O, Geurtsen W. Comparison of the number and diameter of dentinal tubules in human and bovine dentine by scanning electron microscopic investigation. Arch Oral Biol. 2000 May;45(5):355-61.

18. Hara AT, Queiroz CS, Paes Leme AF, Serra MC, Cury JA. Caries progression and inhibition in human and bovine root dentine in situ. Caries Res. 2003 Sep-Oct;37(5):339-44.

19. Young A, Tenuta LM. Initial erosion models. Caries Res. 2011;45 Suppl 1:33-42.

20. Wang Y, Spencer P. Effect of acid etching time and technique on interfacial characteristics of the adhesive-dentin bond using differential staining. Eur J Oral Sci. 2004 Jun;112(3):293-9.

21. Sattabanasuk V, Shimada Y, Tagami J. Bonding of resin to artificially carious dentin. J Adhes Dent. 2005 Autumn;7(3):183-92.

22. Hashimoto $M$, Ohno $H$, Sano $H$, Kaga $M$, Oguchi $H$. In vitro degradation of resin-dentin bonds analyzed by microtensile bond test, scanning and transmission electron microscopy. Biomaterials. 2003 Sep;24(21):3795-803.

23. Tay FR, Pashley DH. Resin bonding to cervical sclerotic dentin: a review. J Dent. 2004 Mar;32(3):173-96.

24. Carrilho MR, Tay FR, Donnelly AM, Agee KA, Tjaderhane L, Mazzoni A, et al. Host-derived loss of dentin matrix stiffness associated with solubilization of collagen. J Biomed Mater Res B Appl Biomater. 2009 Jul;90(1):373-80.

25. Buzalaf MA, Kato MT, Hannas AR. The role of matrix metalloproteinases in dental erosion. Adv Dent Res. 2012 Sep;24(2):72-6.

26. Perdigao J. Dentin bonding-variables related to the clinical situation and the substrate treatment. Dent Mater. 2010 Feb;26(2):e24-37.

27. Yoshida Y, Van Meerbeek B, Nakayama Y, Yoshioka M, Snauwaert J, Abe Y, et al. Adhesion to and decalcification of hydroxyapatite by carboxylic acids. J Dent Res. 2001 Jun;80(6):1565-9.

28. Belli R, Sartori N, Peruchi LD, Guimaraes JC, Araujo E, Monteiro Jr S, et al. Slow progression of dentin bond degradation during one-year water storage under simulated pulpal pressure. J Dent. 2010 Oct;38(10):802-10.

29. Shimaoka AM, Andrade AP, Cardoso MV, Carvalho RC. The importance of adhesive area delimitation in a microshear bond strength experimental design. J Adhes Dent. 2011 Aug;13(4):307-14.

30. Andrade AM, Garcia EJ, El-Askary FS, Reis A, Loguercio AD, Grande RH. Influence of different test parameters on the microshear bond strength of two simplified etch-and-rinse adhesives. J Adhes Dent. 2014 Aug;16(4):323-31. 